\title{
SINTEZA COMPONENŢILOR ACTIVI AI FEROMONILOR SEXUALI SINTETICI A VIERMELUI MERELOR (CYDIA POMONELLA L.) - E8,E10-DODECENOL ȘI A MOLIEI STRUGURILOR (LOBESIA BOTRANA S.) - E7,Z9-DODECADIENOL ŞI COMPONENȚII MINORI A ACESTORA E-8-DODECENOL ŞI E-9- DODECENILACETAT
}

\author{
Odobescu V., Jalbă S., Răileanu N.,Șleahtici $V$. \\ Institutul de Genetică, Fiziologie şi Protecţie a Plantelor, Chişinău, Republica Moldova \\ igpppheromones@gmail.com \\ https://doi.org/10.53040/9789975347204.22
}

\begin{abstract}
The aim of our study was the synthesis of the active components of the apple worm, Cydia pomonella L. - E8, E10-dodecenol and the grape moth, Lobesia botrana S. - E7, Z9dodecadienol and their minor components E-8-dodecenol and E-9 -dodecenyl acetate. Different amounts of components were impregnated in each rubber dispenser. Pheromone traps was given to be tested in field monitoring trials to determine the most effective optimal pheromone blend ratio in the geographical and climatic conditions of the Republic of Moldova.
\end{abstract}

Key words: pheromone traps, apple worm, grape moth, minor components, rubber dispenser, pheromone traps.

\section{Introducere}

Condițiile climaterice din ultimii ani favorizează numărul mare de dăunători în Republica Moldova, printre care dăunătorii viermele merelor, Cydia pomonella L. și molia strugurilor, Lobesia botrana $\mathrm{S}$.

Viermele merelor, Cydia pomonella L. este răspîndit pe toate continentele, este un dăunător major al livezilor de mere, nuci şi de pere, avînd o foarte bună capacitate de adaptare la condițiile de mediu. Larvele produc perforații în pielița fructului în curs de formare și pătrund în fruct formînd galerii, hrănindu-se cu pulpa și semințele fructelor. Fructele tinere atacate se usucă și cad, cele atacate mai tîrziu nu se pot valorifica superior, și nici nu se pot depozita, deoarece se pot instala diverși agenti patogeni[1].

Molia strugurilor, Lobesia botrana (Denis \& Shiffermüller) este dăunătorul major al strugurilor (Vitis vinifera L.) în Europa Centrală și în bazinul mediteranean (Anshelevich și colab., 1994). Daunele provocate de acest dăunător sunt cauzate de hrănirea larvelor sale cu ciorchinii de struguri, ceea ce îi face sensibili la boala putregaiul cenușiu (Botrytis cinerea) la mijlocul sezonului și la colonizarea cu ciuperci. 
Controlul tradițional cu ajutorul produselor chimice a fost principalul instrument de combatere a dăunătorilor în secolul trecut, dar odată cu descoperirea feromonilor sexuali ai insectelor a permis trecerea la agricultura ecologică prin combaterea cu ajutorul unor metode biologice inofensive pentru om și mediul ambiant precum folosirea capcanelor feromonale.

Componentul principal al feromonului sexual a viermelui merelor, C. pomonella $\mathrm{L}$. (E,E)-8,10-dodecadienol -codlemon a fost descoperit de Roelofs et al. în 1971. Studiile ulterioare au arătat că şi alţi compuşi, pe lângă codlemon, sunt implicaţi în atragerea masculilor de viermele merelor. A fost demonstrat în testele de laborator că amestecul format din 5 componenți : codlemonul, E, Z -izomerul său, (E) -9-dodecenol, (E) -8-dodecenol, dodecanolul și tetradecanolul, este mai atractiv decât codlemonul singur[2].

Componentul principal al feromonului sexual a moliei strugurilor, L. botrana S., acetatul de (E, Z) -7,9-dodecadienil a fost descoperit și el în anul 1973 de echipa lui Roelofs, acesta a fost utilizat pe scară largă timp de aproape două decenii împotriva acestui dăunător în Germania, Elveția și în nordul Italiei. Mai târziu au fost identificați și alți compuși, (E, Z) 7,9-dodecadien-1-olul, acetatul de (Z) -9-dodecenil etc. care aveau efect sinergetic asupra insectelor de sex masculin (Arn și colab., 1988; El-Sayed și colab., 1999)[3].

Scopul studiului nostru a fost sinteza componenților activi ai viermelui merelor, Cydia pomonella L.-E8,E10-dodecenol și a moliei strugurilor, Lobesia botrana S.-E7,Z9dodecadienil-acetat şi a componenților minori ai acestora E-8-dodecenol și E-9dodecenilacetat pentru impregnarea formelor preparative cu diferite proporții a componenţilor pentru a fi date la testare în condiții de cîmp pentru determinarea celei mai eficiente compoziții feromonale în condițiile geografice și climaterice a Republicii Moldova.

\title{
Materiale și metode
}

Pentru sinteza în laborator au fost folosiţi reactivi chimici comerciali. Mersul reacţiilor a fost urmărit cu ajutorul cromatografiei în strat subţire. Substanţele intermediare şi finale au fost purificate prin distilare în vacuum şi curăţite pe coloane cu silicagel, puritatea lor a fost testată cu ajutorul cromatografiei în strat subţire. Au fost utilizate diferite metode de sinteză organică fină ca: bromurare, protejarea grupei $-\mathrm{OH}$, alchilare în amoniac lichid, reducerea pînă la alcoolul etilenic, oxidarea cu complexul clorcromatpiridină, Reacţia Wittig, deprotejarea grupei $-\mathrm{OH}$, acetilare, esterificare, reducerea esterului acidului sorbic, clorurarea 1,6-hexandiolului, condensare magneorganică, izomerizare în etilendiamină, regruparea legăturii triple în alcooli acetilenici, reducerea alcoolilor acetilenici în trans-alcooli etilenici ş.a.

\section{Rezultate și discuții}

Schema de sinteza a componentului major a feromonului sexual al viermelui merelor E8,E10- dodecenol

\author{
$\mathrm{HO}\left(\mathrm{CH}_{2}\right)_{6} \mathrm{OH} \rightarrow \mathrm{Cl}\left(\mathrm{CH}_{2}\right)_{6} \mathrm{OH}(1) \rightarrow \mathrm{Cl}\left(\mathrm{CH}_{2}\right)_{6} \mathrm{OR}(2) \rightarrow$ \\ $\mathrm{CH}_{3} \mathrm{CH}=\mathrm{CHCH}=\mathrm{CHCOOH} \rightarrow \mathrm{CH}_{3} \mathrm{CH}=\mathrm{CHCH}=\mathrm{CHCOOC}_{2} \mathrm{H}_{5}(3) \rightarrow$ \\ $\mathrm{CH}_{3} \mathrm{CH}=\mathrm{CHCH}=\mathrm{CHCOH}(4)+\mathrm{Cl}\left(\mathrm{CH}_{2}\right)_{6} \mathrm{OR}(2) \rightarrow$
}

$\mathrm{CH}_{3} \mathrm{CH}=\mathrm{CHCH}=\mathrm{CH}\left(\mathrm{CH}_{2}\right)_{7} \mathrm{OR}(5) \rightarrow \mathrm{CH}_{3} \mathrm{CH}=\mathrm{CHCH}=\mathrm{CH}\left(\mathrm{CH}_{2}\right)_{7} \mathrm{OH}(6)$

Prin clorurarea 1,6-hexandiolului cu acid clorhidric conc. în toluen obținem 
6-clorohexan-1-ol(1), după care protejăm grupa-OH cu 3,4- dihidropiran (2). La interacțiunea acidului sorbic cu alcoolul etilic obținem esterul etilic al acidului sorbic(3), acesta este redus cu hidrura de litiu si aluminiu pînă la alcoolul acidului sorbic(4). La interacțiunea

6-clorohexan-1-ol-ului protejat cu reagentul Grignard și cu alcoolul acidului sorbic se obține E8,E10-decadienol protejat(5), hidroliza acetui compus duce la obținerea componentului principal a viermelui merelor, Cydia pomonella L. - E8,E10-dodecenol.

\section{Schema de sinteză a componentului minor a feromonului sexual al viermelui merelor E8-dodecenol} $\mathrm{HC} \equiv \mathrm{CCH}_{2} \mathrm{OH} \rightarrow \mathrm{C}_{6} \mathrm{H}_{13} \mathrm{C} \equiv \mathrm{CCH}_{2} \mathrm{OH}(1) \rightarrow$

$\mathrm{HC} \equiv \mathrm{C}\left(\mathrm{CH}_{2}\right)_{7} \mathrm{OH}(2) \rightarrow \mathrm{HC} \equiv \mathrm{C}\left(\mathrm{CH}_{2}\right)_{7} \mathrm{OR}(3) \rightarrow$

$\mathrm{C}_{3} \mathrm{H}_{7} \mathrm{C} \equiv \mathrm{C}\left(\mathrm{CH}_{2}\right)_{7} \mathrm{OR}(4) \rightarrow \mathrm{C}_{3} \mathrm{H}_{7} \mathrm{C} \equiv \mathrm{C}\left(\mathrm{CH}_{2}\right)_{7} \mathrm{OH}(5) \rightarrow$

$\mathrm{E}-\mathrm{C}_{3} \mathrm{H}_{7} \mathrm{CH}=\mathrm{CH}\left(\mathrm{CH}_{2}\right)_{7} \mathrm{OH}(6)$

Prin acţiunea alcoolului propargilic cu 1-bromhexan în amoniac lichid se obţine substanţa nonin-2-ol-1 (1) care, în prezenţa amidurii de sodiu şi etilendiamină se transformă în alcoolul nonin-8-ol-1 (2) cu legătura acetilenică terminală. Protecţia grupei hidroxile în alcoolul (2) cu 3,4-dihidropiran duce la acetalul 1-(21-tetrahidropiraniloxi)-8-nonin (3), care după reacţia cu bromura de etil se transformă în 1-(2 ${ }^{1}$-tetrahidropiraniloxi)-dodecin-8 (4). După deprotejarea grupei hidroxile prin hidroliză se obţine alcoolul acetilenic dodecin-8-ol-1 (5), reducerea căruia cu hidrura de litiu si aluminiu în tetrahidrofuran se obţine substanţa trans-8-dodecenol (6). Pentru îndeplinirea scheme propuse mai sus au fost sintetizaţi în laborator: acid bromhidric, bromura de hexan.

\section{Schema de sintezaă a componentului major a feromonului sexual al moliei strugurilor} E7,Z9-dodecadienil acetat

$$
\begin{aligned}
& \mathrm{HO}(\mathrm{CH} 2) 6 \mathrm{OH} \rightarrow \mathrm{Br}(\mathrm{CH} 2) 6 \mathrm{OH}(1) \rightarrow \mathrm{Br}(\mathrm{CH} 2) 6 \mathrm{OR}(2) \rightarrow \\
& \mathrm{HOCH} 2 \mathrm{C} \equiv \mathrm{C}(\mathrm{CH} 2) 6 \mathrm{OR}(3) \rightarrow \mathrm{HOCH} 2 \mathrm{CH}=\mathrm{CH}(\mathrm{CH} 2) 6 \mathrm{OR}(4) \rightarrow \\
& \mathrm{O}=\mathrm{CHCH}=\mathrm{CH}(\mathrm{CH} 2) 6 \mathrm{OR}(5)+\mathrm{C} 2 \mathrm{H} 5 \mathrm{CH} 2 \mathrm{PPh} 3 \mathrm{Br} \rightarrow \\
& \mathrm{C} 2 \mathrm{H} 5 \mathrm{CH}=\mathrm{CH} \mathrm{CH}=\mathrm{CH}(\mathrm{CH} 2) 6 \mathrm{OR}(6) \rightarrow \\
& \mathrm{C} 2 \mathrm{H} 5 \mathrm{CH}=\mathrm{CH} \mathrm{CH}=\mathrm{CH}(\mathrm{CH} 2) 6 \mathrm{OH}(7) \rightarrow \\
& \mathrm{C} 2 \mathrm{H} 5 \mathrm{CH}=\mathrm{CH} \mathrm{CH}=\mathrm{CH}(\mathrm{CH} 2) 6 \mathrm{OCOCH} 3 \\
& \mathrm{R}=\text { tetrahidropiraniloxi }
\end{aligned}
$$

La acţiunea 1,6 -hexandiol-ului cu acidul bromhidric concentrat în toluen se obţine 6-bromohexan-1-ol(1) care după protejarea grupei hidroxil cu 3,4-dihidropiran duce la bromacetal(2). Alchilarea substanţei (2) cu alcool propargilic în amoniac lichid dă alcoolul acetilenic (3) care cu ajutorul hidrurii de litiu și aluminiu se reduce în trans-alcoolul etilenic (4), care după oxidarea cu complexul clorcromatpiridină în clorură de metilenă se transformă în trans-aldehida (5). Mai departe, trans-aldehida (5) reacţionează cu sarea organică din 
bromură de propil şi trifenilfosfină după reacţia Wittig în condiţiile cis-izomeriei cu obţinerea dodecadienacetalei (6). Hidroliza acetalei (6) cu acid sulfuric în alcool etilic dă E7,Z9dodecadienol (7) care după acţiunea cu clorură de acetil se transformă în acetatul E7,Z9dodecadienol (8) - feromonul sexual al moliei strugurilor. Preparatul căpătat este compus din 86-88\% trans-7,cis-9-izomer, 10\% trans-7,trans-9-izomer şi 2-4\% alţi doi izomeri.

\title{
Schema de sinteză a componentului minor a feromonului sexual al moliei strugurilor Z9-dodecenil acetat
}

\author{
$\mathrm{C}_{7} \mathrm{H}_{15} \mathrm{OH} \rightarrow \mathrm{C}_{7} \mathrm{H}_{15} \mathrm{Br}(1) \rightarrow$ \\ $\mathrm{C}_{7} \mathrm{H}_{15} \mathrm{C} \equiv \mathrm{CCH}_{2} \mathrm{OH}(2) \rightarrow \mathrm{HC} \equiv \mathrm{C}\left(\mathrm{CH}_{2}\right)_{8} \mathrm{OH}(3) \rightarrow$ \\ $\mathrm{HC} \equiv \mathrm{C}\left(\mathrm{CH}_{2}\right)_{8} \mathrm{OR}(4)+\mathrm{C}_{2} \mathrm{H}_{5} \mathrm{Br} \rightarrow \mathrm{C}_{2} \mathrm{H}_{5} \mathrm{C} \equiv \mathrm{C}\left(\mathrm{CH}_{2}\right)_{8} \mathrm{OR} \quad(5) \rightarrow$ \\ $\mathrm{C}_{2} \mathrm{H}_{5} \mathrm{C} \equiv \mathrm{C}\left(\mathrm{CH}_{2}\right)_{8} \mathrm{OH}(6) \rightarrow$ cis- $\mathrm{C}_{2} \mathrm{H}_{5} \mathrm{CH}=\mathrm{CH}\left(\mathrm{CH}_{2}\right)_{8} \mathrm{OH}(7) \rightarrow$
}

cis- $\mathrm{C}_{2} \mathrm{H}_{5} \mathrm{CH}=\mathrm{CH}\left(\mathrm{CH}_{2}\right)_{8} \mathrm{OCOCH}_{3}$

La bromurarea 1-heptanolului cu acid bromhidric conc. se formează 1-bromoheptanol care la alchilarea cu alcoolul propargilic în amoniac lichid are loc introducerea legăturii triple terminale și formarea alcoolului acetilenic respectiv(2). Izomerizarea acestuia sub acţiunea $\mathrm{NaNH}_{3}$ şi etilendiaminei duce la obținerea de alcool acetilenic cu legătura triplă în poziția 9 (3) care se protejează prin interacțiunea cu 3,4-dihidropiran (4). Alchilarea acestuia cu etilbromid duce la lungirea catenei cu 2 atomi de carbon (5), care la hidroliză dă alcoolul dodec-9-in-1-ol (6), iar la hidrogenizarea acestuia cu etilendiamină şi catalizatorul de Nichel se reduce în cis-alcoolul etilenic (7) care la acetilare cu clorură de acetil se transformă în Z9dodecenil acetat $(8)$.

În rezultatul efectuării schemelor de sinteză expuse mai sus au fost obținuți componenții principali a feromonilor sexuali a viermelui merelor, Cydia pomonella E8,E10-dodecadienol și a moliei strugurilor, Lobesia botrana Schiff -E7,Z9-dodecadienil acetat.

Deasemenea au fost sintetizați și componenții minori a feromonului sexual al viermelui merelor, Cydia pomonella - E8-dodecenol și a moliei strugurilor, Lobesia botrana Schiff - Z9-dodecenil acetat.

Componentul de bază -E8,E10-dodecadienol a fost impregnat pe toate formele preparative în concentraţie de $0,57 \mathrm{mg}$, la ele au fost adăugate următoarele concentraţii de E8dodecenol în cantitate de $0,3 \%, 0,6 \%, 0,9 \%$ la o capsulă.

Componentul de bază - E7,Z9-dodecadienil acetat a fost impregnat pe toate formele preparative în concentraţie de $0,6 \mathrm{mg}$, la ele au fost adăugate următoarele concentraţii de Z9dodecenil acetat în cantitate de $0,003 \%, 0,006 \%, 0,009 \%$ la o capsulă.

Formele preparative impregnate au fost date pentru studierea influenței componenţilor minori în cadrul compoziţiei feromonale în condiţii de cîmp asupra eficacităţii biologice a feromonului la monitorizarea şi capturarea în masă a dăunătorului.

\section{Concluzii}

1. Au fost sintetizați componenții principali a feromonilor sexuali a viermelui merelor, Cydia pomonella - E8,E10-dodecadienol și a moliei strugurilor, Lobesia botrana -

E7,Z9-dodecadienil acetat. 
2. Au fost sintetizați componenții minori a feromonului sexual al viermelui merelor Cydia pomonella - E8-dodecenol și a moliei strugurilor, Lobesia botrana - Z9-dodecenil acetat.

3. Componenții majori și minori, pentru prima dată în Republica Moldova, au fost combinați în diferite proporții și compozițiile date au fost impregnate pe forme preparative.

4. Formele preparative impregnate în diferite proporții cu substanțele biologic active obținute în laborator au fost date spre testarea în condiții de cîmp pentru determinarea eficacității biologice a compozițiilor feromonale în condițiile climaterice a Republicii Moldova.

\section{Bibliografie}

1. Muhammad Faheem Malik, Arshad Ghani Khan, Abdul Karim Jafer, Liaquat Ali , Sohail Anwar and Akhtar Munir, 2002. Codling Moth, Cydia pomonella (Lepidoptera: Tortricidae); As a Major Pest of Apple. Asian Journal of Plant Sciences, 1: 288-291.

2. $\quad$ Ashraf El-Sayed, Marie Bengtsson, Stefan Rauscher, Jan Lo“ Fqvist, Peter Witzgall. Multicomponent Sex Pheromone in Codling Moth (Lepidoptera: Tortricidae). Environmental Entomology Vol. 28, no. 5

3. C. Ioriatti, G. Anfora, M. Tasin, A. De Cristofaro, P. Witzgall , and A.

Lucchi. Chemical Ecology and Management of Lobesia botrana (Lepidoptera: Tortricidae) Journal of Economic Entomology, 104(4):1125-1137. 2011. 